\title{
Optimizing pesticide spray coverage using a novel web and smartphone tool, SnapCard
}

\author{
Christian Nansen ${ }^{1,2}$ • J. Connor Ferguson ${ }^{3}$. John Moore ${ }^{5}$ - Lloyd Groves ${ }^{1}$. \\ Rob Emery ${ }^{5}$ - Nicolas Garel ${ }^{6}$ - Andrew Hewitt ${ }^{3,4}$
}

Accepted: 14 April 2015 / Published online: 22 May 2015

(C) INRA and Springer-Verlag France 2015

\begin{abstract}
The overuse of pesticides leads to contamination of water and food. Therefore, there is a need for tools and strategies to optimize pesticide application. Here we present SnapCard, a user-friendly and freely available decision support tool for farmers and agricultural consultants, available at snapcard.agric.wa.gov.au. SnapCard allows to predict, measure, and archive pesticide spray coverage quantified from water-sensitive spray cards. Variables include spray settings such as nozzle orifice size, sprayer speed, water carrier rate and adjuvant, and weather variables such as barometric pressure, relative humidity, temperature, and wind speed at ground level. We use separate regression models for four nozzles types. Our results showed that there are strong and positive correlations between water carrier rate and spray coverage for all four nozzle types. Moreover, sprayer speed is highly negatively correlated with obtained spray coverage. In addition, there is no consistent effect of either nozzle type or use of a
\end{abstract}

Christian Nansen

chrnansen@ucdavis.edu

1 School of Animal Biology, The UWA Institute of Agriculture, The University of Western Australia, 35 Stirling Highway, Crawley, Perth, WA 6009, Australia

2 Department of Entomology and Nematology, UC Davis, Briggs Hall, Room 367, Davis, CA, USA

3 Centre for Pesticide Application and Safety, The University of Queensland Gatton, Gatton, QLD 4343, Australia

4 WCREC, University of Nebraska-Lincoln, 402 W State Farm Rd, North Platte, NE 69101, USA

5 Department of Agriculture and Food, Western Australia (DAFWA), 3 Baron-Hay Court, South Perth, WA 6151, Australia

6 NGperceptive, http://www.ngperceptive.com particular adjuvant, across water carrier intervals. We conclude that varying combinations of spray settings and weather conditions caused marked ranges of spray coverages among the four nozzle types, thus highlighting the importance of selecting the right nozzle orifice size and type. We demonstrate that realistic scenarios of environmental conditions and spray settings can lead to predictions of very low spray coverage with at least one of the four nozzle types. We discuss how the novel and freely available smartphone app, SnapCard, can be used to optimize spray coverage, reduce spray drift, and minimize the risk of resistance development in target pest populations.

Keywords Integrated pest management $\cdot$ Pesticide spraying · Western Australia $\cdot$ Pesticide performance $\cdot$ Decision support tool

\section{Introduction}

Based on reviews of global trends affecting current food production systems worldwide (Nansen and Ridsdill-Smith 2013; Bon et al. 2014; Liu et al. 2014; Popp et al. 2013), it is predicted that a wide range of agricultural and horticultural production systems will face an increase in pest pressures and therefore also in numbers of pesticide spray applications (Bon et al. 2014; Liu et al. 2014; Martínez-Blanco et al. 2013) (Fig. 1a). Similar to Bon et al. (2014), we consider the term "pesticide" to encompass all chemicals used to control economic pests (i.e. weeds, fungi, arthropods, and nematodes). Although exact figures are not available for many countries, there are fairly sobering estimates of the global use and applications of pesticides. Liu et al. (2014) calculated that, on an annual basis, at least 20 countries apply over $2 \mathrm{~kg}$ of insecticides per hectare of harvested agricultural land. The 
Fig. 1 Ground rig spray application (a) and a watersensitive spray card placed in a sprayed potato field (b).

Screenshot of the SnapCard tool to predict spray coverage based on spray setting and weather conditions (c). SnapCard can be used to quantify spray coverage based on image analysis of watersensitive spray cards placed in sprayed fields (d)
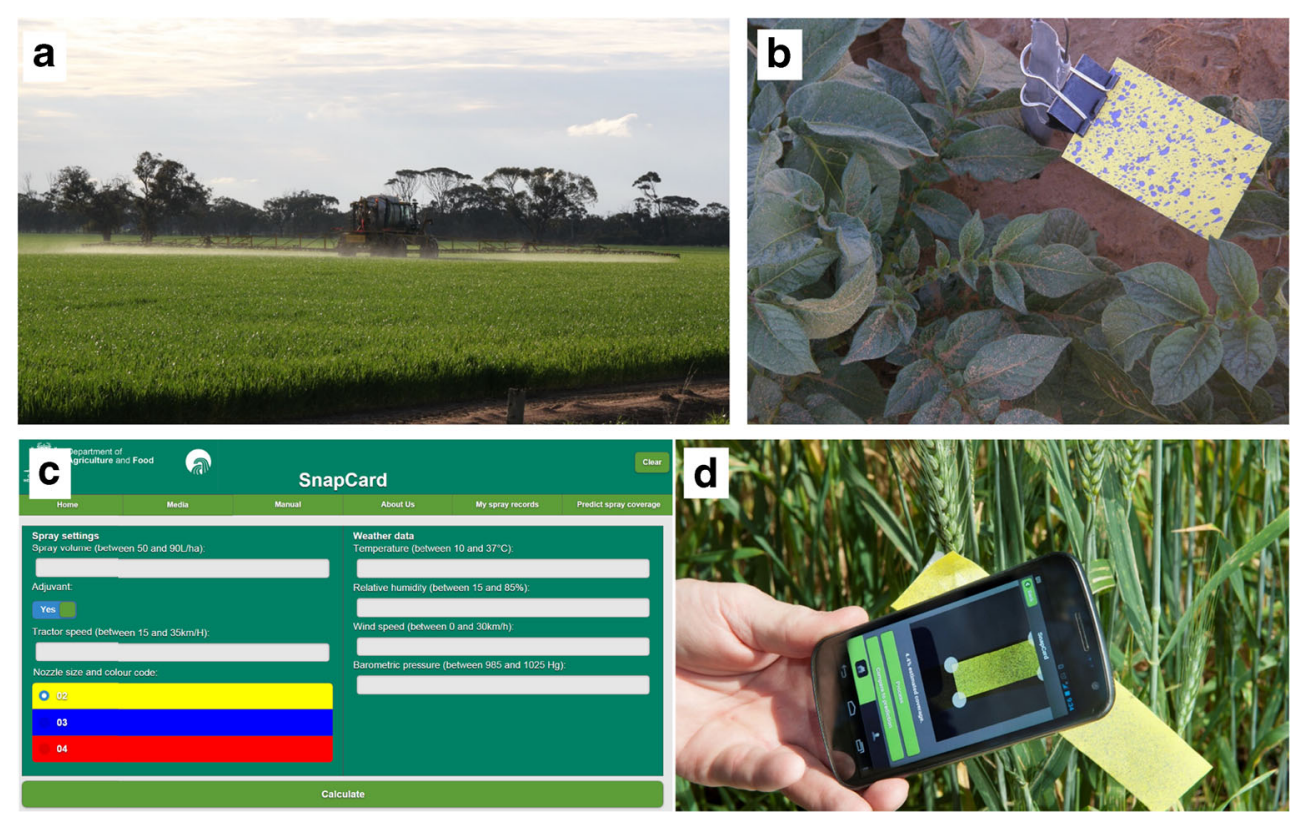

annual pesticide market has been estimated to be worth approximately USD 0.9 billion in Africa alone (Bon et al. 2014) and approximately USD 40 billion globally (Popp 2011; Popp et al. 2013). These statistics underscore the role pesticide applications play in current food production systems. With average farm size growing and at the same time being managed by fewer employees, pesticide spray applications are being applied by (a) driving ground rigs at higher speeds or using aerial applications, so that more area can be treated within imposing time constraints; (b) using less water carrier with nozzles delivering smaller droplets, so that less time is spent on refilling pesticide tanks; and (c) spraying during times when ambient conditions are likely to increase the risk of spray drift and/or low and inconsistent spray coverage. The current analysis contributes with quantitative information about how choice of pesticide spray practices may affect the performance and sustainability of these applications.

Spray coverage is the proportional area covered by the pesticide formulation droplets (water carrier, active ingredients, and adjuvants) onto treated surfaces, such as crop leaves (Fig. 1b). A low spray coverage means that target arthropod pests in a crop canopy are presented with choices between treated and untreated portions of crop leaves. A possible consequence of low and inconsistent pesticide spray coverages is that target pests develop behavioral avoidance or resistance (Georghiou 1972), and it has been documented in several arthropod species, including German cockroaches [Blatella germanica L. (Dictyoptera: Blattellidae)] (Hostetler and Brenner 1994; Wang et al. 2004), diamondback moths (Plutella xylostella L, Lepidoptera: Plutellidae) (Sarfraz et al. 2007; Jallow and Hoy 2007, 2006), and spider mites [Tetranychus cinnabarinus Boisduval (Acari: Tetranychidae)] (Martini et al. 2012). Likely consequences of low spray coverage and target pests developing behavioral avoidance/resistance include reduced pest suppression and therefore an increase in number of applications (because after a spray failure, farmers have to come back and spray again), increased risk of environmental contaminations, and potential loss of agricultural productivity. There are also quantitative analyses highlighting that low dosage of herbicide applications (which is an indirect effect of low spray coverage) may lead to increased risk of weed species developing resistance (Renton et al. 2011, 2014; Powles and Yu 2010; Mortensen et al. 2012).

Due to the growing understanding of the importance of spray coverage as part of smart and sustainable management of agricultural and horticultural systems, there is a demand for innovative, user-friendly, and readily available (ideally free) decision support tools for field use by farmers and agricultural consultants to predict and measure quality and performance of spray applications based on weather conditions and spray settings. Numerous methods have been used to quantify coverage from spray applications in repeatable and consistent manners under field conditions, and these methods have been reviewed in a number of studies over the last 45 years (Turner and Huntington 1970; Bateman 1993; Giles and Downey 2003; Crowe et al. 2005). A commonly used practice is to deploy water-sensitive spray cards prior to spray applications (Fig. 1b). These are coated with a bromoethyl blue dye that turns blue in the presence of water (Hill and Inaba 1989; Turner and Huntington 1970; Syngenta 2002). These cards can provide an immediate assessment of spray coverage to make real-time decisions about the performance of ongoing or planned spray applications in agricultural and horticultural systems (Hill and Inaba 1989; Degre et al. 2001; Cunha et al. 2012, 2013; Hoffman and Hewitt 2005; Garcia et al. 2004). 
Numerous studies have described the complex relationships between spray settings, weather conditions, and spray deposition, and this ongoing research has led to development of a number of commercially available decision support tools, including the Swath $\mathrm{Kit}^{\circledR}$ (Mierzejewski 1991), USDA image analysis (Hoffman and Hewitt 2005), DropletScan ${ }^{\circledR}$ scanner (Wolf 2003), Optomax ${ }^{\circledR}$ (Syngenta 2002), and AgroScan ${ }^{\circledR}$ (http://www.agrotec.etc.br/produtos/agroscan/). There are also studies describing the development of algorithms for quantification of the homogeneity of the spray spatial spread and droplet size distributions (Marçal and Cunha 2008). However, these decision support tools are not freely available, and they require equipment other than a smartphone. Furthermore, the only method available to assess spray coverage under field conditions is a qualitative comparison with brochure or a manual counting system provided by pesticide and spray equipment manufacturers.

In this study, we describe the regression model outputs associated with "SnapCard", a combined website (http:// snapcard.agric.wa.gov.au) and smartphone app, which is freely available via the Apple iTunes and Android Google Play stores. The main objective with SnapCard is to provide farmers, agricultural consultants, and researchers with a simple decision support tool with two main functionalities: (1) pre-application prediction/forecasting of spray coverage based on weather data and spray settings, and (2) postapplication measurement, quality control/auditing of spray coverage by comparing observed/actual with the predicted coverage. SnapCard is based on results from 898 spray trials with replicated water-sensitive spray cards $(N=1796$ spray cards) acquired over three growing seasons at three locations in Western Australia. In each trial, we quantified spray coverage (based on digitized water sensitive papers), measured weather conditions, tested a wide range of spray settings (sprayer speed, nozzle type and flow rate, water carrier rate, and tank pressure).

\section{Materials and methods}

\subsection{Simplified calculation of a theoretical spray coverage}

Before interpreting spray coverages obtained under experimental spray trials, it was considered useful to provide a highly simplified estimate of the theoretical spray coverage (elimination of all physical and environmental effects). Consider a spray application of $100 \mathrm{~L} /$ ha of a pesticide formulation, which is equal to $10 \mathrm{~mL} / \mathrm{m}^{2}$. If the average droplet diameter is $100 \mu \mathrm{m}$, then $10 \mathrm{~mL}$ is approximately 19 million droplets, and the theoretical spray coverage would be $0.6 \mathrm{~m}^{2} / \mathrm{m}^{2}$ or $60 \%$. This calculation is based on the assumption that the total surface area is completely flat and horizontal (the total surface area of a three-dimensional crop canopy is ignored), that the droplets are uniformly distributed, and that the entire volume of pesticide formulation is deposited on target surfaces (no drift and/or evaporation). In Western Australia, commercial pesticide spray applications in field crops are often conducted with 70-80 L/ha water carrier rates and combinations of nozzle orifice size and tank pressure, which delivers droplets with an average diameter of 200-250 $\mu \mathrm{m}$; this means that the theoretical (highest possible if no drift and evaporation occur) spray coverage is $20 \%$ or lower. These simple calculations appear to justify some general concern about the performance of pesticide spray applications when the potential spray coverage is that low. Furthermore, it highlights an aspect of pest management practices, in which more quantitative decision support tools, assessment methods, and clearer guidelines are needed.

\subsection{Calculation of spray coverage}

In this study, quantification of spray coverage was based on water-sensitive spray cards $(5.1 \mathrm{~cm} \times 7.6 \mathrm{~cm}$, Syngenta, Wilmington, DE, USA), which are coated with bromoethyl blue and turn from yellow to blue/purple depending on dosage of water (Hoffman and Hewitt 2005; Nansen et al. 2011). Each spray card was labeled and stored in dry dark conditions prior to analysis in the laboratory. Spray coverage was a percentage measurement of blue/purple on individually digitized yellow spray cards. Analysis involved digitization using a color scanner at a spatial resolution of 5000 pixels $/ \mathrm{cm}^{2}$, and image analysis using Image J $1.45 \mathrm{~s}$ (http://imagej.nih.gov) to determine the percentage of blue pixels (water droplets) on each spray card. Using threshold settings in ImageJ, the color image was converted into an 8-bit black/white image, and the following YUV color space settings were used as thresholds: $Y=172, U=255$, and $V=255$. This method of quantifying spray coverage of pesticides has been widely used (Hill and Inaba 1989; Degre et al. 2001; Cunha et al. 2012, 2013; Hoffman and Hewitt 2005; Garcia et al. 2004; Martini et al. 2012; Nansen et al. 2011; Sánchez-Hermosilla and Medina 2004), and Hill and Inaba (1989) also found a strong and positive correlation between spray coverage and dosage of active ingredient on sprayed surfaces.

\subsection{Experimental spray trials}

Experimental spray applications were conducted on 11 separate days between June 2012 and June 2014 at three locations in Western Australia (Albany, -35.026920, 117.883801; Shenton Park, -31.950397, 115.798016; and Mingenew $-29.198569,115.438181)$. On each day of spray applications, we collected data with all 12 combinations of nozzle type and orifice size, so that we have the same number of observations and replications from all 11 days of spray applications. For each experimental spray application, two water-sensitive 
spray cards, about $1.2 \mathrm{~m}$ apart, were secured in a horizontal position $15 \mathrm{~cm}$ above a bare soil surface immediately before each spray application. In this study, the complexity of agricultural fields and its impact on pesticide movement was ignored, as we quantified spray coverages on horizontally placed spray cards above bare ground. This enabled direct comparison of effects of spray settings and weather conditions, but it also means that predicted spray coverages should be considered "relative" to an experimental standard.

Only water or water with the labeled rate $(0.1 \%$ by volume) of a non-ionic surfactant (SP700 surfactant, Genfarm, Landmark Operations, New South Wales, Australia) was sprayed. This adjuvant was chosen because we had anecdotal evidence of its widespread use in Australian agriculture. We tested effects of the following spray settings: (1) sprayer speed $(15-35 \mathrm{~km} / \mathrm{h}$ ), (2) flat fan nozzle type (AIXR110, TP110, XR110, and TT110), (3) nozzle orifice size (02, 03, and 04), and (4) water carrier rate (35-140 L/ha). Regarding nozzle orifice size. The values for nozzle orifices $(\div 10$, e.g. 0.3$)$ indicate the liquid flow rate of the nozzle in US gallons per minute at 2.76 bar pressure ( 1 US gallon=3.785 L).

Four commonly used nozzles in Australia are the Spraying Systems ${ }^{\circledR}$ Teejet ${ }^{\circledR}$ TT, TP, XR, and AIXR. TP is a tapered flat fan nozzle, XR is an extended range flat fan nozzle, and TT is a Turbo Teejet nozzle with an anvil shape which reduces liquid velocity thereby increasing average droplet diameter. The TP and XR nozzles have a similar droplet size spectrum at the same pressure and flow rate, but the spray velocities and coefficient of variation patterns may have differed. The XR denotes "extended range" and can be used at a greater range of pressures than the TP series. The TT (Turbo Teejet) nozzles produce larger droplets than the TP and XR series under similar conditions. The AIXR is an extended range flat-fan nozzle with air inclusion, creating larger droplets than the TT, TP, and XR series for the same flow rate by introducing air bubbles into individual droplets. If these air bubbles remain in the droplet to the point of deposition on a leaf, they may facilitate its spread to cover a larger area prior to drying.

The total data set consisted of spray coverage from 1796 water-sensitive spray cards and accompanying weather variables and spray settings. However, for 308 of the watersensitive spray cards, the nozzle flow rate was unknown, so these data were not included in analyses involving this explanatory variable.

In all spray trials, a weather station (Kestrel 4500 Pocket Weather Tracker) was used in an open area of the field being sprayed to collect on-site weather data at $50 \mathrm{~cm}$ above ground level in 1-min intervals. The measurements included ambient temperature and dew point $\left({ }^{\circ} \mathrm{C}\right)$, relative humidity $(\%)$, wind speed $(\mathrm{km} / \mathrm{h})$, and barometric pressure $(\mathrm{mmHg})$. These variables were chosen because they are readily available or could be easily measured with a standard weather station.

\subsection{Statistical analysis of spray coverage data}

All analyses of spray coverage data were conducted using PCSAS 9.1 (SAS Institute, Cary, NC), and the objective was to quantify the relative influences of spray settings and weather conditions on both spray coverage and spray deposition efficiency (spray coverage/spray carrier rate). Spray coverages were arcsine transformed prior to statistical analyses. The water carrier rates ranged from 35 to $140 \mathrm{~L} / \mathrm{ha}$ (131 different rates), and for average comparisons, the applications were divided into $10-\mathrm{L}$ water carrier classes. All water carrier rates from 100 to $140 \mathrm{~L} /$ ha were grouped into a single water carrier class due to the low number of observations $(N=63)$.

It is important to highlight that spray coverage may not be linearly correlated with water carrier rate, as an increase in water carrier rate increases the chance of a droplet landing on a part of the water-sensitive card that already has a droplet (Hewitt and Valcore 2002). Thus, an initial regression analysis (PROC REG) was used to examine the direct effect of water carrier rate on spray coverage. PROC ANOVA was used to examine the effects of nozzle type, and use of a particular adjuvant was examined for each of the eight water carrier classes. PROC REG with linear, quadratic, and cubic responses was used to examine effects of sprayer speed on spray coverage. The same multi-regression approach was also used to examine effects of water carrier rate and nozzle flow rate on the obtained spray coverage. Finally, PROC REG was used to examine effects of all spray settings and weather variables on obtained spray coverages. In this latter analysis, forward stepwise selection was used to only select explanatory variables that contributed significantly to the regression fit.

\subsection{SnapCard}

The SnapCard app can be downloaded from Apple iTunes and Android Google Play stores by searching for snapcard. A manual for download, installation, and use of SnapCard is available at http://snapcard.agric.wa.gov.au, and a brief description is provided below. There are two complementary and inter-connected components of SnapCard: (1) a website and (2) a smartphone app. The interconnection of the two components is based on a user-defined login. The main functionalities of the website are (1) to introduce different combinations of spray settings and environmental conditions (Fig. $1 c)$ to predict spray coverage with four different nozzle types, and (2) record-keeping of results from previous spray applications. In spray coverage predictions, it is only possible to generate predictions within the minimum and maximum ranges of the data used to generate the predictive models: nozzle orifice size $(2,3$ or 4$)$, sprayer speed $(15-35 \mathrm{~km} / \mathrm{h})$, water carrier rate $(50-90 \mathrm{~L} / \mathrm{ha})$, adjuvant $(\mathrm{no}=0$, yes $=1)$, barometric pressure (985-1025 mm Hg), relative humidity (15- 
$85 \%$, ambient temperature $\left(10-37^{\circ} \mathrm{C}\right)$, and wind speed at ground level $(0-30 \mathrm{~km} / \mathrm{h})$.

The main functionalities of the smartphone app are to allow field prediction of spray coverage and to conduct quality control of completed spray applications by photographing water-sensitive spray cards in the field using the smartphone camera (Fig. 1d). SnapCard records the GPS coordinates of the spray card and digitizes and quantifies droplet coverage. The user takes a photo of each spray card and crops the photo to process only the area of interest, i.e. the spray card. After quantification of spray coverages obtained from actual spray applications, these estimates can be compared directly with model predictions (based on spray settings and environmental conditions) as a form of quality control. Treatment information, personnel, spray settings, environmental data, predicted coverage, measured coverage, spray card photo, and GPS coordinates can all be archived on the secure SnapCard website.

\section{Results and discussion}

\subsection{Effects of water carrier rate and nozzle type and flow rate}

As expected, there was a clear and positive correlation between spray carrier rate and spray coverage (Fig. 2a). For each of the eight water carrier classes, we conducted analyses of variance to compare average spray coverages across nozzle types and found that (1) in six of the water carrier classes, TT nozzles generated significant lower spray coverage rates than TP and AIXR nozzles $(P<0.05)$, and $(2)$ there were no significant differences in average spray coverage rates obtained with TP and AIXR nozzles for any of the eight water carrier classes $(P>0.05)$. A simple comparison of average spray coverage rates obtained with TP and TT nozzles revealed a $20 \%$ difference across eight water carrier classes. Regarding spray deposition (spray coverage/water carrier), TP nozzles showed the highest spray coverage at low water carrier rates and at rates above $100 \mathrm{~L} / \mathrm{ha}$, AIXR nozzles had the highest performance at mid-range water carrier rates, and XR nozzles had the highest spray coverage at high water carrier rates (Fig. 2b). Thus, selection of spray nozzles appears to markedly influence the spray coverage of pesticide formulations to sprayed crops.

Figure 3 shows the relative effects of nozzle flow rate and water carrier rate on spray coverage for the four nozzle types, and it is seen that (1) TT (Fig. 3b) and XR (Fig. 3c) nozzles showed quite similar and linear effects of water carrier rate and only negligible effect of nozzle orifice size, (2) TP nozzles showed a modest but exponential spray coverage response to water carrier rate and a unimodal response to nozzle orifice size with 03 nozzles providing higher spray coverage than 02 and 04 nozzles (Fig. 3a), and (3) AIXR nozzles also showed a unimodal response to nozzle orifice size but an asymptotic response to water carrier rate (Fig. 3d). None of the examined nozzle flow rates showed a strong synergistic response between water carrier rate and nozzle orifice size. With 04 nozzles producing larger droplets than 02 nozzles, it could be speculated that an increase in nozzle orifice size would have a negative effect on spray coverage due to a reduction in droplet density. However, smaller droplets also increase the risk of spray drift and may therefore cause a reduction in spray coverage if lost from the target. The results in Fig. 3 are important, because they highlight that nozzle orifice size in itself is not a particularly important factor when attempting to optimize spray coverage. These findings are supported by Ramsdale and Messersmith (2001),
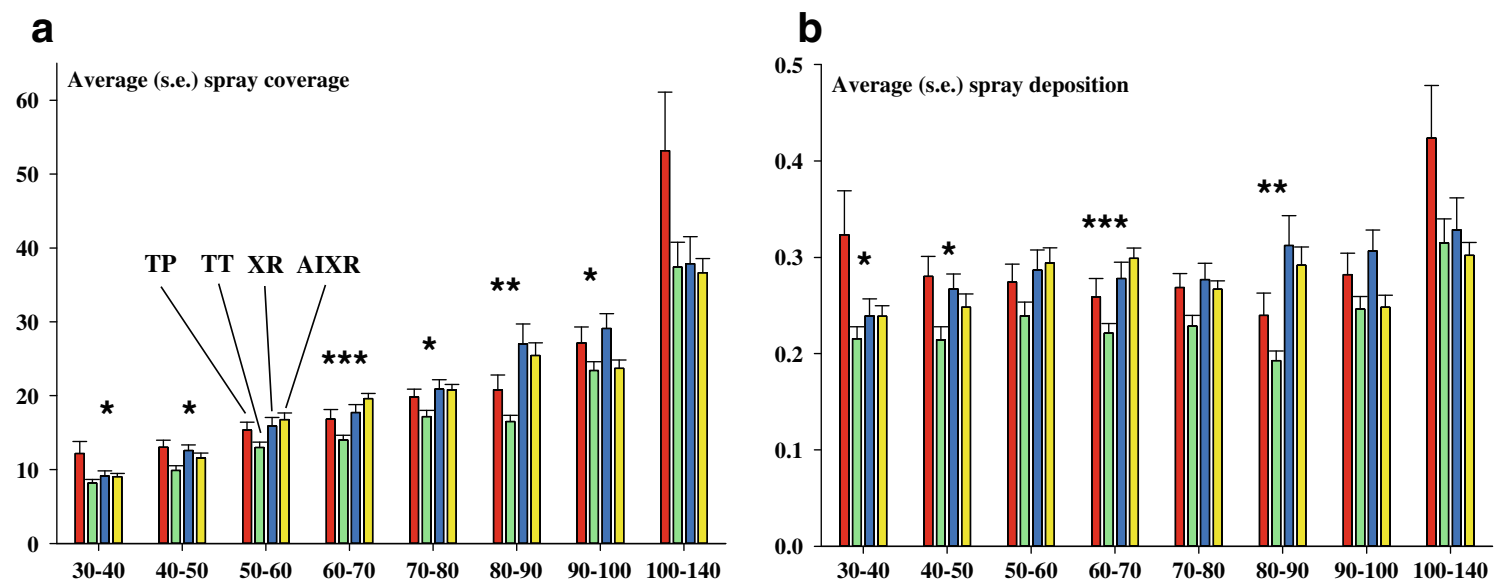

Fig. 2 Average spray coverage (a) and spray deposition (spray coverage/water carrier rate) (b) with four nozzle types (TP, TT, XR, and AIXR) from digitized water-sensitive spray cards by water carrier class. “*”, “**”, and “***” denote significant difference at the $0.05,0.01$, and 0.001 levels 
Fig. 3 Response surfaces of nozzle flow rate $(02,03$, and 04$)$ and water carrier rate $(\mathrm{L} / \mathrm{ha})$ for each of the four nozzle types: TP (a), TT (b), XR (c), and AIXR (d)
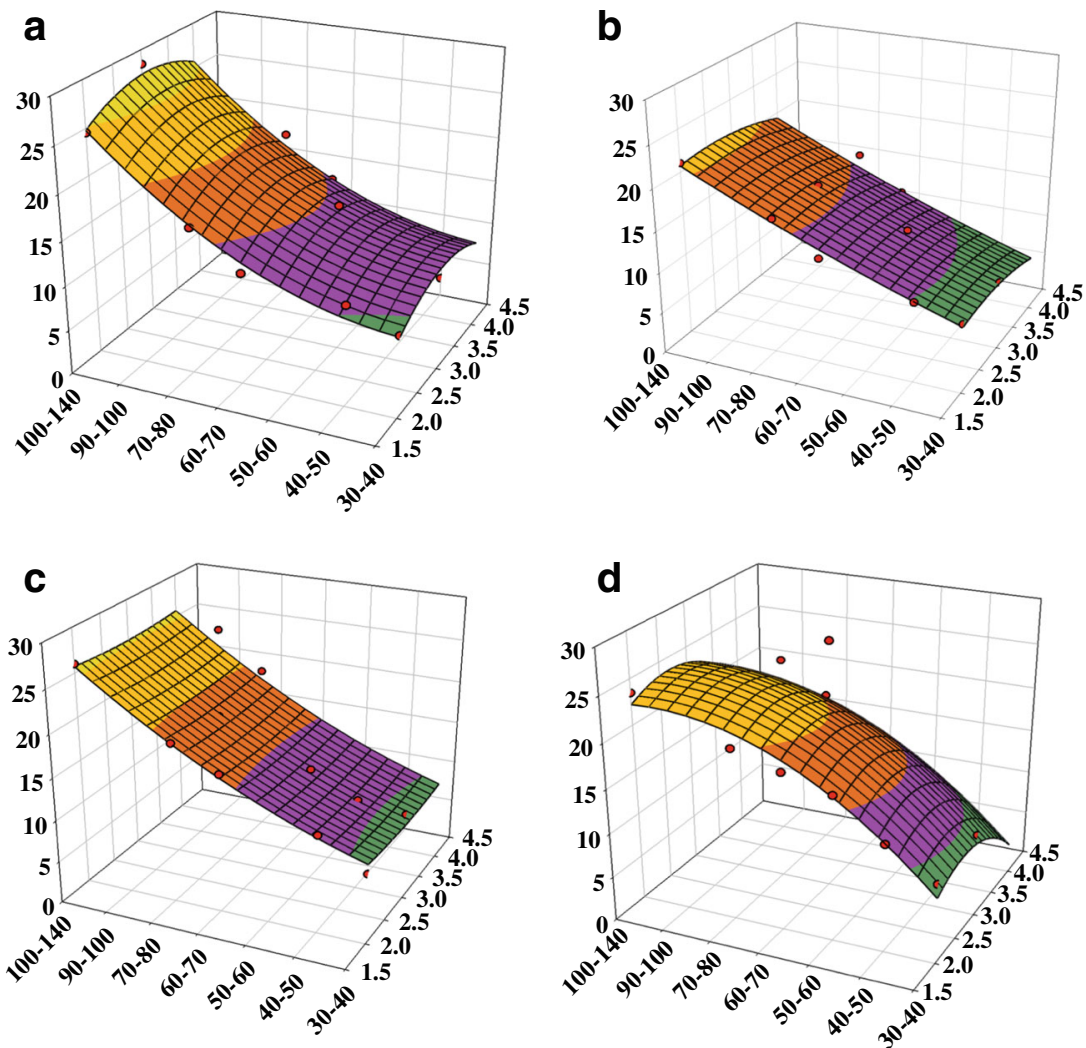

who also found that nozzle type was not a key factor affecting coverage; instead, it was higher water carrier rates that increased spray coverage.

\subsection{Effects of spray settings and weather conditions}

We obtained spray coverage data across abiotic ranges, which were considered representative for broad-acre spray application conditions in Western Australia and elsewhere (Table 1). Due to the nozzle-specific results in the different water carrier classes, we conducted separate analyses for each type of nozzle. For the 1488 spray cards for which we had weather data and all spray settings [including carrier volume rate (L/ha)], we calculated predicted spray coverages, which were subsequently divided into the eight water carrier classes (Fig. 4), and it is seen that predicted spray coverages align strongly with actual spray coverages presented in Fig. 2a. The effects of spray settings and weather conditions on spray coverage (coverage quantified from digitized water-sensitive spray cards) showed that (Table 2) (1) all four regression analyses provided highly significant fits of spray settings and weather conditions to spray coverage, and (2) different combinations of spray settings and weather conditions contributed significantly to the four regression models. It was beyond the scope of this article to provide in-depth analyses of the selected variables and their relative importance for the different nozzle types. Instead, we wish to interpret the results presented in
Table 2 in a broader context and focus on the possible sustainability and performance implications of choice of spray nozzles, spray settings, and the effects of weather conditions during spray applications.

Table 3 lists seven spraying scenarios (combinations of spray settings and weather conditions) and the predicted spray coverages with each of the four nozzle types. The scenarios were created so that only one variable (highlighted in a rectangular box) was modified in pairwise comparisons. Also, these scenarios are believed to be representative of spray settings and weather conditions in Western Australia and many other regions with significant agricultural and horticultural production system. The only difference between scenarios 1 and 2 was the water carrier rate ( 40 and $60 \mathrm{~L} / \mathrm{ha}$ ), and it can be seen that the predicted spray coverages with four nozzle types were very similar under scenario 1 (19-23\% spray coverage)-however, increasing the water carrier rate by $50 \%$ (from 40 to $60 \mathrm{~L} / \mathrm{ha}$ ) only caused considerable increases (15-27\%) in predicted spray coverages with three nozzle types (predicted spray coverage with AIXR nozzles decreased slightly, which is considered anomalous). However, if the sprayer speed is reduced from 25 to $15 \mathrm{~km} / \mathrm{h}$ (scenarios 2 and 3 ), then quite high spray coverages (25-30\%) were predicted with all four nozzle types. In the comparison of scenarios 3 and 4, we slightly reduced the barometric pressure and showed that predicted spray coverages with AIXR nozzles were unaffected, TP and XR nozzles decreased, and TT 
Table 1 Meteorological conditions during experimental spray trials

\begin{tabular}{|c|c|c|c|c|c|}
\hline Date & Location & Wind speed $(\mathrm{km} / \mathrm{h})$ & Temperature $\left({ }^{\circ} \mathrm{C}\right)$ & Relative humidity (\%) & Barometric pressure $(\mathrm{mmHg})$ \\
\hline $02 / 06 / 12$ & Mingenew & 17.9 & 28.2 & 23.1 & 1017.0 \\
\hline $03 / 06 / 12$ & Mingenew & 21.7 & 19.4 & 24.8 & 1020.0 \\
\hline $04 / 07 / 12$ & Albany & 14.2 & 12.2 & 56.9 & 1026.0 \\
\hline $07 / 03 / 13$ & Mingenew & 10.6 & 36.4 & 15.2 & 990.5 \\
\hline $08 / 03 / 13$ & Mingenew & 6.7 & 30.3 & 36.4 & 993.2 \\
\hline $04 / 04 / 13$ & Shenton Park & 5.3 & 34.9 & 26.0 & 1014.7 \\
\hline $13 / 05 / 13$ & Shenton Park & 5.9 & 18.3 & 59.4 & 1027.4 \\
\hline $07 / 06 / 13$ & Shenton Park & 2.9 & 21.0 & 43.5 & 1021.2 \\
\hline $02 / 07 / 13$ & Mingenew & 13.3 & 19.2 & 34.1 & 986.7 \\
\hline $13 / 05 / 14$ & Albany & 6.6 & 19.7 & 47.1 & 1011.7 \\
\hline $16 / 06 / 14$ & Shenton Park & 6.1 & 20.6 & 35.9 & 1017.9 \\
\hline
\end{tabular}

Date format is day/month/year

nozzles increased. In the comparison of scenarios 4 and 5, the barometric pressure was decreased further and coverage dropped accordingly for all nozzles with TP nozzles showing the strongest reduction in spray coverage. In scenarios 5 and 6 , it was seen that the negative of high barometric pressure could be partially mitigated through an increase in water carrier rate. However, as indicated in the comparison of scenarios 6 and 7 , an increase in ambient temperature caused markedly different effects on the four nozzle types: (1) spray coverages with AIX and TT nozzles increased, and (2) spray coverages with TP and AIXR nozzles decreased starkly (spraying with TP nozzles equal to $0 \%$ spray coverage). Due to the extremely low spray coverage obtained with TP nozzles, we examined two additional scenarios with TP nozzles only and showed that increasing the water carrier rate to 100 and $110 \mathrm{~L} / \mathrm{ha}$ resulted in spray coverage predictions of 5.2 and $13 \%$, respectively. Thus, the take-home message is that spraying with TP nozzles

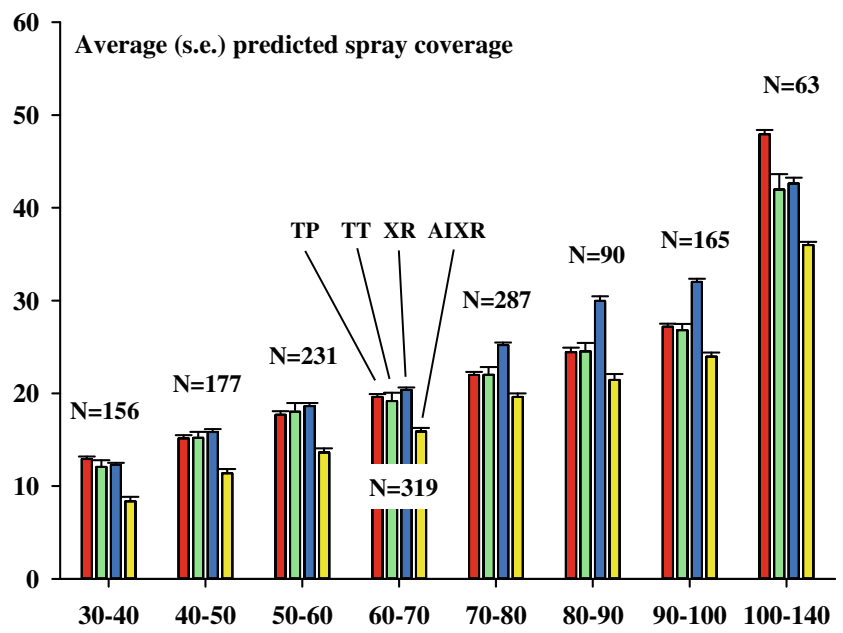

Fig. 4 Average predicted spray coverage rates with four nozzle types (TP, TT, XR, and AIXR) by water carrier class. Numbers above columns denote numbers of observations in each water carrier class appears to be quite sensitive to certain weather conditions and may require higher water carrier rates than other nozzles types. The last three scenarios in Table 3 were included to demonstrate that different realistic combinations of spray settings and weather variables can lead to predictions of very low spray coverage with at least one of the four nozzle types. Very low spray coverages suggest that the combination of evaporation and spray drift was delivering a large proportion of the sprayed water to non-target surfaces.

\subsection{SnapCard predictions and spray coverages published elsewhere}

It should be re-iterated that predicted spray coverages refer to percentage coverage on a water-sensitive spray card placed in a horizontal position, and that no crop canopy was present. In other words, the obtained spray coverage should be considered the highest possible coverage under the given combinations of spray settings and weather variables. If spray applications had been applied to a real crop canopy, the spray coverage in the bottom portion would probably have been somewhat lower. Based on water carrier rates used in Western Australian cropping systems, we did not include water carrier rates higher than $140 \mathrm{~L} / \mathrm{ha}$. However, elsewhere, including the USA, water carrier rates typically range from 60 to $200 \mathrm{~L} / \mathrm{ha}$, and it is not uncommon, especially with aerial spray applications (and therefore low water carrier rates), for spray coverages to be considerably below $20 \%$ (Latheef et al. 2008a, b; Wolf and Daggupati 2009; Nansen et al. 2011; Derksen et al. 2012). In vineyards and fruit orchards, much higher water carrier rates $(250-1000 \mathrm{~L} / \mathrm{ha})$ are applied, and spray coverages may reach $50 \%$ (Marçal and Cunha 2008). Nansen et al. (2011) collected spray data from eight pesticide applications with fixed-wing aircraft and six with ground rigs to commercial potato fields in Texas. The highest average spray coverage (measured as percentage spray coverage on water-sensitive 
Table 2 Explanatory variables and corresponding coefficients selected to predict spray coverage with four different nozzle types

\begin{tabular}{|c|c|c|c|c|c|}
\hline Variable & Effect & AIXR & $\mathrm{TP}$ & $\mathrm{TT}$ & $\mathrm{XR}$ \\
\hline Intercept & & -23948 & 409.326 & -29056 & -17019 \\
\hline Adjuvant $($ yes $=1$, no $=0)$ & Linear & 4.14524 & 4.09616 & 1.87622 & 3.57237 \\
\hline Nozzle flow rate $(02,03,04)$ & Linear & 5.60814 & & & \\
\hline Nozzle flow rate $(02,03,04)$ & Cubic & & -0.068 & & \\
\hline Speed $(\mathrm{km} / \mathrm{h})$ & Linear & -2.65839 & 3.5063 & & \\
\hline Speed $(\mathrm{km} / \mathrm{h})$ & Quadratic & 0.06254 & -0.1457 & & \\
\hline Speed $(\mathrm{km} / \mathrm{h})$ & Cubic & -0.00063 & 0.00191 & $-6 \mathrm{E}-05$ & \\
\hline Water carrier rate $(\mathrm{L} / \mathrm{ha})$ & Linear & -0.59959 & 0.8967 & 0.2567 & -0.0987 \\
\hline Water carrier rate $(\mathrm{L} / \mathrm{ha})$ & Quadratic & 0.00564 & -0.0123 & -0.0016 & 0.00637 \\
\hline Water carrier rate $(\mathrm{L} / \mathrm{ha})$ & Cubic & $-1.4 \mathrm{E}-05$ & $7.5 \mathrm{E}-05$ & $1.2 \mathrm{E}-05$ & $-3 \mathrm{E}-05$ \\
\hline Barometric pressure $(\mathrm{mmHg})$ & Linear & 35.88505 & -1.2913 & 57.7348 & 24.9027 \\
\hline Barometric pressure $(\mathrm{mmHg})$ & Quadratic & & & -0.0287 & \\
\hline Barometric pressure $(\mathrm{mmHg})$ & Cubic & $-1.2 \mathrm{E}-05$ & $5.4 \mathrm{E}-07$ & & $-8 \mathrm{E}-06$ \\
\hline Relative humidity (\%) & Linear & -2.30352 & & 0.19025 & 2.83881 \\
\hline Relative humidity (\%) & Quadratic & 0.05108 & & & -0.0769 \\
\hline Relative humidity (\%) & Cubic & -0.00025 & $-5 \mathrm{E}-05$ & $3.5 \mathrm{E}-05$ & 0.00065 \\
\hline Temperature $\left({ }^{\circ} \mathrm{C}\right)$ & Linear & 0.72254 & 47.4516 & 2.28432 & 29.6785 \\
\hline Temperature $\left({ }^{\circ} \mathrm{C}\right)$ & Quadratic & & -2.2696 & -0.0372 & -1.3611 \\
\hline Temperature $\left({ }^{\circ} \mathrm{C}\right)$ & Cubic & -0.00023 & 0.03385 & & 0.01944 \\
\hline Wind Speed $(\mathrm{km} / \mathrm{h})$ & Linear & & & 0.38825 & 0.21802 \\
\hline Wind Speed $(\mathrm{km} / \mathrm{h})$ & Cubic & 0.000471 & & -0.0003 & \\
\hline Observations & & 476 & 346 & 316 & 350 \\
\hline Adjusted $R^{2}$ & & 0.682 & 0.614 & 0.748 & 0.581 \\
\hline
\end{tabular}

spray cards placed in a horizontal position at the top of the crop canopy) was approximately $67 \%$ with ground rig applications. On average, the bottom portion of the potato canopy received $50 \%$ less spray coverage than the top portion.

The possible short-term economic and long-term sustainability implications of low spray coverages are quite farreaching and complex. Before addressing these implications separately, we assume that low spray coverage and deposition of the active ingredient onto treated surfaces are positively correlated. We wish to acknowledge that this assumption could be considered controversial and disputed, as very fine droplets containing a high dosage of pesticide could go undetected in the quantification of spray coverage based on watersensitive spray cards. Thus, it is possible to imagine a low spray coverage with a high deposition of pesticide. Few studies have quantified the relationships between spray coverage and delivery of pesticide to sprayed surfaces, but there seems to be some support for the assumption that low spray coverage means that target pests are exposed to a lower dosage of the pesticide (Hill and Inaba 1989).

Table 3 Predicted spray coverages with four nozzles types

$\begin{array}{lcccccccc} & \text { No. 1 } & \text { No. 2 } & \text { No. 3 } & \text { No. 4 } & \text { No. 5 } & \text { No. 6 } & \text { No. 7 } \\ \text { Adjuvant } & 1 & 1 & 1 & 1 & 1 & 1 & 1 \\ \text { Nozzle flow rate } & 2 & 2 & 2 & 2 & 2 & 2 & 2 \\ \text { Speed }(\mathrm{km} / \mathrm{h}) & 25 & 25 & 15 & 15 & 15 & 15 & 15 \\ \text { Water carrier rate } & 40 & 60 & 60 & 60 & 60 & 90 & 90 \\ \text { Barometric pressure (mm Hg) } & 1020 & 1020 & 1020 & 1000 & 985 & 985 & 985 \\ \text { Relative humidity }(\%) & 55 & 55 & 55 & 55 & 55 & 55 & 55 \\ \text { Temperature }\left({ }^{\circ} \mathrm{C}\right) & 18 & 18 & 18 & 22 & 22 & 22 & 28 \\ \text { Wind speed }(\mathrm{km} / \mathrm{h}) & 12 & 12 & 12 & 12 & 12 & 12 & 12 \\ \text { Predicted spray coverages } & & & & & & & 26.5 \\ \text { AIX } & 19.2 & 16.4 & 25.7 & 36.3 & 24.2 & 24.7 & 26.5 \\ \text { TP } & 20.7 & 25.3 & 25.1 & 7.8 & 3.4 & 13.0 & 0.0 \\ \text { TT } & 22.5 & 26.2 & 26.9 & 35.3 & 24.1 & 30.05 & 33.1 \\ \text { XR } & 23.3 & 29.5 & 29.5 & 22.4 & 8.4 & 18.9 & 8.4\end{array}$




\subsection{Possible short-term economic and long-term sustainability implications of low spray coverage}

Most (if not all) pest populations are known to show dosage response to pesticides, and there are also studies showing dosage response to spray coverage (Nansen et al. 2011). Thus, the immediate effect of low spray coverage (and therefore low dosage applied) is that less target pests are killed. In other words, the time and resource investments in pesticide applications become less meaningful due to poor performance. At the same time, low pest suppression increases the needs for pesticide applications (as farmers have to treat again after a pesticide application with low performance), so the economic implications of low spray coverage may be considerable.

The short-term economic implications are concerning, but it is probably even more important to examine the possible long-term effects of low spray coverage. Such long-term effects of pesticides may be studied and quantified through genetic population modeling, which has been an important research area since ground-breaking work in the 1970s (Georghiou and Taylor 1977, 1976). This type of population modeling is based on the fundamental assumption that genetic variability exists within a given target pest population and that certain low-frequency alleles are associated with proportionally higher survival. Thus, applications of pesticides should be considered a selection pressure imposed by humans, and the sustainability of a particular pesticide becomes a matter of resistance management: how to kill enough pests to avoid economic losses but at the same time not impose a strong and persistent selection pressure leading to resistance in the target pest population and shortening the useful life of the pesticide. Many factors influence the actual level of pesticide resistance development in a pest population, including the following (Nansen and Ridsdill-Smith 2013; Gassmann et al. 2009; Georghiou and Taylor 1976; Renton et al. 2011, 2014): (1) genetic factors (i.e. frequency, dominance, and expressivity of resistant alleles and their interactions with other alleles, fitness costs associated with resistance, past selection pressures in pest population, and whether the resistance is monogenic or polygenic), and (2) biological factors (fecundity, generation and development times, mating behavior, level of polyphagy, migration/dispersal and mobility, fitness costs of resistance development, and feeding biology).

Georghiou and Taylor (1977) conducted a series of simulations and demonstrated that low pesticide dosage delayed the development of resistant allele frequency because of lower selection pressure. However, low pesticide dosage also meant very poor pest suppression. Imposing a strong selection pressure through application of high dosage caused a rapid increase in the resistant allele frequency, but it also meant that the overall population level was kept low for numerous pest generations. Georghiou and Taylor (1977) also examined the effects of threshold-based pesticide applications (only applying pesticides when the pest density is above a certain threshold), and they showed that the potential benefits of this approach was particularly important when resistance was associated with a fitness cost. Regarding resistance in weeds and low-dosage herbicide applications, Renton et al. (2011) conducted modeling and demonstrated no effect of dosage on the risk of monogenic resistance but an increased risk of herbicide resistance in certain cases of polygenic resistance, when weeds are exposed to low-dosage herbicide regimes. All genetic population modeling studies focus exclusively in genetic/physiological resistance; however, animals such as insects are also known to potentially develop behavioral resistance or avoidance (Martini et al. 2012; Wang et al. 2004; Hostetler and Brenner 1994).

The main conclusions from genetic population modeling studies appear to be that both high- and low-dosage (spray coverage) applications may lead to resistance development, although resistance may develop slower under low-dosage application regimes. As discussed by recent authors (Whalon et al. 2008; Nansen and Ridsdill-Smith 2013; Renton et al. 2014) and publicly available databases (the Arthropod Pesticide Resistance Database (APRD, http://www.pesticideresistance.org/), a main characteristic of most known pests is their ability to develop resistance to pesticides. With the continuously growing list of pesticides becoming ineffective due to resistance, insecticides being phased out due to concerns about their adverse environmental effects, and with chemical companies having to spend increasing amounts of resources on getting new active ingredients registered for commercial use, it seems reasonable to reflect on the longterm sustainability of the current pesticide application practices. There is a growing need for improved stewardship of the existing pesticides, and it is paramount to enhance the understanding of how to use them effectively. We are therefore arguing that low-coverage pesticide application scenarios should be avoided, as they represent a selection pressure which will contribute to resistance development, and they will most likely provide only limited pest suppression.

\section{Conclusion}

It is important to highlight that optimization of pesticide spray coverage is challenging as two opposing factors with similar priorities are in play: On one hand, optimization of pesticide applications is about maximizing the spray coverage with small droplets (as there is a negative correlation between droplet diameter and total surface of droplets); on the other hand, smaller droplets are more likely to drift (Byass and Lake 1977; 
Bouse et al. 1990) and to be associated with low canopy penetration (where many pests are most abundant). Recently, the concept of pesticide transfer models was reviewed and mathematical tools were used to predict the flow and dispersal of pesticides when sprayed onto fields with a range of variables affecting the pesticide fate, such as tillage, mulching, and weed and crop characteristics (Mottes et al. 2014).

This analysis highlighted two important aspects of pesticide spray coverage: (1) environmental factors affect spray coverages in different ways, and there are likely complex (non-linear) interactions, which are only identifiable through modeling, and (2) nozzle types responded differently to combinations of spray setting and environmental factors, and the highest spray coverage was not always obtained with the same nozzle type. Thus, optimized selection of both nozzle type and orifice size is not trivial and should therefore be based on the use of quantitative decision support tools, such as Snapcard. The fundamental difference between calendar-based pesticide applications and integrated pest management (IPM) practices is that IPM is decision-based, and responsive interventions, such as pesticide applications, are only conducted on a "when needed basis" and with "need" typically being defined by an action threshold (Pedigo and Rice 2006). Here, we argue that not only is pest density action threshold important but also predicted/expected performance should be taken into considerations before pesticide applications are deployed, as that will likely increase the sustainability of pesticide-based pest management.

\section{References}

Bateman R (1993) Simple, standardized methods for recording droplet measurements and estimation of deposits from controlled droplet applications. Crop Prot 12(3):201-206

Bon H, Huat J, Parrot L, Sinzogan A, Martin T, Malézieux E, Vayssières J-F (2014) Pesticide risks from fruit and vegetable pest management by small farmers in sub-Saharan Africa. A review. Agron Sustain Dev 34:723-736. doi:10.1007/s13593-014-0216-7

Bouse LF, Kirk IW, Bode LE (1990) Effect of spray mixture on droplet size. Trans ASAE 33(3):783-788

Byass JB, Lake JR (1977) Spray drift from a tractor-powered field sprayer. Pestic Sci 8(2):117-126

Crowe TG, Downey D, Giles DK (2005) Digital device and technique for sensing distribution of spray deposition. Trans ASAE 48(6):20852093

Cunha M, Carvalho C, Marcal ARS (2012) Assessing the ability of image processing software to analyse spray quality on water-sensitive papers used as artificial targets. Biosyst Eng 111:11-23

Cunha JPAR, Farnese AC, Olivet JJ (2013) Computer programs for analysis of droplets sprayed on water sensitive papers. Planta Daninha 31(3):715-720

Degre A, Mostade O, Huyghebaert B, Tissot S, Debouche C (2001) Comparison by image processing of target supports of spray droplets. Trans ASAE 44(2):217-222
Derksen RC, Paul PA, Ozkan HE, Zhu H (2012) Field evaluations of application techniques for fungicide spray deposition on wheat and artificial targets. Appl Eng Agric 28(3):325-331

Garcia LC, Ramos HH, Justino A (2004) Evaluation of software for analysis of spraying parameters carried over water-sensitive papers (Availação de softwares para análise de parâmetros da pulverização realizada sobre papéis hidrossensíveis). Rev Bras Agrocomputação 2(1):19-28

Gassmann AJ, Carrière Y, Tabashnik BE (2009) Fitness costs of insect resistance to Bacillus thuringiensis. Annu Rev Entomol 54:147-163

Georghiou OP (1972) The evolution of resistance to pesticides. Annu Rev Ecol Evol Syst 3:133-168

Georghiou GP, Taylor CE (1976) Genetic and biological influences in the evolution of insecticide resistance. J Econ Entomol 70:319-323

Georghiou GP, Taylor CE (1977) Pesticide resistance as an evolutionary phenomenon. In: Proceedings of the 15th International Conference of Entomology, Washington, DC, pp 759-785

Giles DK, Downey D (2003) Quality control verification and mapping for chemical application. Precis Agric 4(1):103-124

Hewitt AJ, Valcore DL (2002) Best practices to conduct spray drift studies. In: Lee PW, Aizawa H, Barefoot AC, Murphy JJ (eds) Residue analytical methods handbook for agrochemicals, vol I. John Wiley and Sons, Inc., Chichester

Hill BD, Inaba DJ (1989) Use of water-sensitive paper to monitor the deposition of aerially applied insecticides. J Econ Entomol 82(3): 974-980

Hoffman WC, Hewitt AJ (2005) Comparison of three imaging systems for water-sensitive papers. Appl Eng Agric 21:961-964

Hostetler ME, Brenner RJ (1994) Behavioral and physiological resistance to insecticides in the german cockroach (Dictyoptera: Blattellidae) - an experimental reevaluation. J Econ Entomol 87: 885-893

Jallow MFA, Hoy CW (2006) Quantitative genetics of adult behavioral response and larval physiological tolerance to permethrin in diamondback moth (Lepidoptera: Plutellidae). J Econ Entomol 99: 1388-1395

Jallow MFA, Hoy CW (2007) Indirect selection for increased susceptibility to permethrin in diamondback moth (Lepidoptera : Plutellidae). J Econ Entomol 100:526-533

Latheef MA, Carlton JB, Kirk IW, Hoffmann WC (2008a) Aerial electrostatic-charged sprays for deposition and efficacy against sweet potato whitefly (Bemisia tabaci) on cotton. Pest Manag Sci 65:744-752

Latheef MA, Kirk IW, Bouse LF, Carlton JB, Hoffmann WC (2008b) Evaluation of aerial delivery systems for spray deposition and efficacy against sweet potato whitefly on cotton. Appl Eng Agric 24: 415-422

Liu Y, Pan X, Li J (2014) A 1961-2010 record of fertilizer use, pesticide application and cereal yields: a review. Agron Sustain Dev 1-11. doi:10.1007/s13593-014-0259-9

Marçal ARS, Cunha M (2008) Image processing of artificial targets for automatic evaluation of spray quality. Trans ASABE 51(3):811-821

Martínez-Blanco J, Lazcano C, Christensen TH, Muñoz P, Rieradevall J, Møller J, Antón A, Boldrin A (2013) Compost benefits for agriculture evaluated by life cycle assessment. A review. Agron Sustain Dev 33(4):721-732. doi:10.1007/s13593-013-0148-7

Martini X, Kincy N, Nansen C (2012) Quantitative impact assessment of spray coverage and pest behavior on contact pesticide performance. Pest Manag Sci. doi:10.1002/ps.3330

Mierzejewski K (1991) Aerial spray technology: possibilities and limitations for control of pear thrips. Towards understanding Thysanoptera. USDA Forest Service New England, USA

Mortensen DA, Egan JF, Maxwell BD, Ryan MR, Smith RG (2012) Navigating a critical juncture for sustainable weed management. Bioscience 62(1):75-84. doi:10.1525/bio.2012.62.1.12 
Mottes C, Lesueur-Jannoyer M, Le Bail M, Malézieux E (2014) Pesticide transfer models in crop and watershed systems: a review. Agron Sustain Dev 34(1):229-250. doi:10.1007/s13593-013-0176-3

Nansen C, Ridsdill-Smith TJ (2013) The performance of insecticides - a critical review. In: Trdan S (ed) Insecticides. InTech Europe, Croatia, pp 195-232. doi:10.5772/53987

Nansen C, Vaughn K, Xue Y, Rush C, Workneh F, Goolsby J, Troxclair N, Anciso J, Gregory A, Holman D, Hammond A, Mirkov E, Tantravahi P, Martini X (2011) A decision-support tool to predict spray deposition of insecticides in commercial potato fields and its implications for their performance. J Econ Entomol 104(4):11381145. doi:10.1603/EC10452

Pedigo L, Rice M (2006) Entomology and Pest Management. Fifth edn. Prentice Hall

Popp J (2011) Cost-benefit analysis of crop protection measures. J Consum Protect Food Saf 6:105-112. doi:10.1007/s00003-0110677-4

Popp J, Pető K, Nagy J (2013) Pesticide productivity and food security. A review. Agron Sustain Dev 33(1):243-255. doi:10.1007/s13593012-0105-X

Powles SB, Yu Q (2010) Evolution in action: plants resistant to herbicides. Annu Rev Plant Biol 61:317-347

Ramsdale BK, Messersmith CG (2001) Drift-reducing nozzle effects on herbicide performance. Weed Technol 15(3):453-460

Renton M, Diggle A, Sudheesh M, Powles S (2011) Does cutting herbicide rates threaten the sustainability of weed management in cropping systems? J Theor Biol 283:14-27
Renton M, Busi R, Neve P, Thornby D, Vila-Aiub M (2014) Herbicide resistance modelling: past, present and future. Pest Manag Sci 70: 1394-1404. doi:10.1002/ps.3773

Sánchez-Hermosilla J, Medina R (2004) Adaptive threshold for droplet spot analysis using water-sensitive paper. Appl Eng Agric 20(5): 547-551. doi:10.13031/2013.17454

Sarfraz M, Dosdall LM, Keddie BA (2007) Resistance of some cultivated Brassicaceae to infestations by Plutella xylostella (L.) (Lepidoptera: Plutellidae). J Econ Entomol 100:215-224

Syngenta (2002) Water-sensitive paper for monitoring spray distributions. Syngenta Crop Protection, CH-4002, Basel

Turner CR, Huntington KA (1970) The use of a water sensitive dye for the detection and assessment of small spray droplets. J Agric Eng Res 15(4):385-387

Wang CL, Scharf ME, Bennett GW (2004) Behavioral and physiological resistance of the German cockroach to gel baits (Blattodea: Blattellidae). J Econ Entomol 97:2067-2072

Whalon ME, Mota-Sanchez D, Hollingworth RM (2008) Analysis of global pesticide resistance in arthopods. In: Whalon ME, MotaSanchez D, Hollingworth RM (eds) Global pesticide resistance in arthopods. CABI, Oxfordshire, pp 5-32

Wolf RE (2003) Assessing the ability of DropletScan to analyze spray droplets from a ground operated sprayer. Appl Eng Agric 19(5): 525-530

Wolf RE, Daggupati NP (2009) Nozzle type effect on soybean canopy penetration. Appl Eng Agric 25:23-30 